\title{
Mixing thermodynamic properties of ester-containing solutions: A study on the ternary (methyl alkanoate (pentanoate and methanoate) + methanol) and the corresponding binaries. New contributions to the (ester + ester) interactions
}

\author{
Luís Fernández, Juan Ortega*, Noelia Pérez, Francisco Toledo \\ Laboratorio de Termodinámica y Fisicoquímica de Fluidos, Parque Científico-Tecnológico, 35017-Universidad de Las Palmas de Gran Canaria, Canary Islands, Spain
}

\section{A R T I C L E I N F O}

\section{Article history:}

Received 11 August 2014

Received in revised form 3 February 2015

Accepted 20 February 2015

Available online 28 February 2015

\section{Keywords:}

Mixing properties

Binaries

Ternary

Methyl esters

Methanol

Correlation

NMR

UNIFAC

\begin{abstract}
A B S T R A C T
This work studies the volumetric $\left(V_{\mathrm{m}}^{\mathrm{E}}\right)$ and energetic $\left(H_{\mathrm{m}}^{\mathrm{E}}\right)$ properties resulting from the mixing processes of binary systems and the corresponding ternary of two methyl esters (methanoate and pentanoate) with methanol. The three binaries produce net endothermic mixing effects, with important energetic interactions, with maximum values of $H_{\mathrm{m}}^{\mathrm{E}} \cong 400 \mathrm{~J} \cdot \mathrm{mol}^{-1}$, for the (ester + ester) system. This produces expansive effects $V_{\mathrm{m}}^{\mathrm{E}}>0$, but the binaries of the (methyl esters + methanol) give rise to contractions $V_{\mathrm{m}}^{\mathrm{E}}<0$, due to the formation of molecular aggregates. The endothermicity in the mixing processes is a net effect which is justified by interactions of different nature, especially dipolar interactions and hydrogen bonds of the substances involved. The overall results in the ternary respond to the individual contributions of the binaries and the increment due to the simultaneous presence of the three compounds in the solution. The experimental results are correlated with our own model that gives a good representation of the properties of the solutions studied. The analysis of the behavior of the solutions is reinforced by spectral data obtained by ${ }^{1} \mathrm{H}$ NMR, supporting the structural model established. The application of UNIFAC to estimate the $H_{\mathrm{m}}^{\mathrm{E}}$ in the ternary improves when one takes into account the individual contributions of the (ester + ester) interactions whose parameter are predetermined.
\end{abstract}

(c) 2015 Elsevier Ltd. All rights reserved.

\section{Introduction}

The line of work followed by our research team aims to understand the behavior of systems containing esters with alkanols, compounds present in some biodiesel. Some works in this field [1-7], have provided a large amount of experimental data of interest for studies into biofuels and the design of equipment. However, the experimental information produced is still insufficient, especially that referred to certain structural aspects of those solutions and their physicochemical behavior. Some of these points have been addressed in a previous work [8] on a ternary of two ethyl esters with dodecane, where interesting and useful information was presented about the mutual interactions between ethylic esters, which is also of value for the analysis proposed here.

One of the justifications of this line of work is that the growing demand for energy makes it necessary to find new sources and technologies, with less environmental impact. Hence, some

\footnotetext{
* Corresponding author. Tel.: +34928 459548.

E-mail address: juan.ortega@ulpgc.es (J. Ortega).
}

research focuses on searching for more environmentally-friendly fuels, which are less polluting and have better $\mathrm{O} / \mathrm{C}$ ratios. This can be achieved by using additives that facilitate combustion and reduce emissions. Families of compounds such as ethers and alkanols have been tested as additives for gasoline [9-11] and biodiesel engines [12,13]. In some patents [14,15] methyl methanoate is proposed use as an additive in fuels, for its high $\mathrm{O} / \mathrm{C}$ ratio. The advantage of using additives is that they can be used without significant changes in existing combustion systems. Another known alternative is to use bioalkanols and biodiesel, which can provide some environmental benefits [16], although they present less calorific power [17].

Our investigations on properties of solutions of compounds of this nature that may provide additional information are included in this research line. Mixing quantities were obtained, $V_{\mathrm{m}}^{\mathrm{E}}$ and $H_{\mathrm{m}}^{\mathrm{E}}$ at $T=298.15 \mathrm{~K}$ of the ternary (methyl pentanoate (1) + methyl methanoate (2) + methanol (3)) and their corresponding binaries. Methyl pentanoate was chosen as a candidate for study [18] forming part of a biodiesel produced by transesterification with methanol. The presence of methyl methanoate as an additive has already 
been exposed. We are especially interested in determining the behavior of (ester + ester) solutions, especially the nature of the interactions of (methyl pentanoate + methyl methanoate), which can provide information on the role of this additive in solution, to supplement a previous initial study [8], since there are very few studies on (ester + ester) solutions [19]. Studies in this field show that these solutions present very weak enthalpic effects, but that these reach significant levels when the esters have very different polarities, even without taking into account effects due to hydrogen bonds and their repercussions on the mixing processes of the alkyl alkanoates, mainly derived from the strongest organic acids (formic $>$ acetic $>$ etc.).

For the systems studied, the literature contains $V_{\mathrm{m}}^{\mathrm{E}}[20]$ and $H_{\mathrm{m}}^{\mathrm{E}}$ [21] data for the binary (methyl methanoate (2) + methanol (3)), which are used for purposes of comparison. However, data were not found for the two binaries containing methyl pentanoate. For purposes of clarification, the experimental values obtained are correlated with our own model that has produced good results in previous works $[7,8]$, for which the parameters need to be identified. Conclusions about the behavior of these systems are supported by a spectral analysis obtained by ${ }^{1} \mathrm{H}-\mathrm{NMR}$. Some aspect of the modeling, whose usefulness is interesting to optimize the processes mentioned, is carried out using the evaluation of results obtained by theoretical methods employed in process simulators, such as the UNIFAC method [22]. Special interest is to check if the numerical values of the $\mathrm{HCOO} / \mathrm{COOC}$ interaction in binaries affect the results of solutions of more than two components.

\section{Experimental}

\subsection{Materials}

The products used, of high commercial quality, were supplied by Aldrich. The purity was verified by GC, giving values almost identical to those indicated by the manufacturer, see table 1 . However, products were degassed by ultrasound for several hours and stored in topaz-colored bottles (over $0.3 \mathrm{~nm}$ Fluka molecular sieve), in the dark for several days to remove traces of moisture. Esters and methanol are hygroscopic, so the water content was determined by Karl-Fisher coulometric titration, approximating $50 \mathrm{ppm}$ in all cases. After these operations, the quality of the products was verified again by GC and was found to have a slight improvement for some substances, compared to initial values. The most important characteristics of the products: refractive index $n_{\mathrm{D}}$, and density $\rho$, at $T=298.15 \mathrm{~K}$, are recorded in table 2 , and are comparable to data published in the literature.

The apparatus were calibrated using bidistilled water $\left[\rho=997.04 \mathrm{~kg} \cdot \mathrm{m}^{-3}(T=298.15 \mathrm{~K})\right]$ and degassed in our laboratory, and nonane $\left[\rho=713.85 \mathrm{~kg} \cdot \mathrm{m}^{-3}(T=298.15 \mathrm{~K})\right]$, which was subjected to the same treatment indicated above for other products; the quality and the source of these substance are given in table 1 .
TABLE 2

Experimental densities $\rho$, and refractive indices measured at $T=298.15 \mathrm{~K}$ and atmospheric pressure, of the pure compounds and comparison with those from literature.

\begin{tabular}{|c|c|c|c|c|}
\hline \multirow[t]{2}{*}{ Compounds } & \multicolumn{2}{|c|}{$\rho / \mathrm{kg} \cdot \mathrm{m}^{-3}$} & \multicolumn{2}{|l|}{$\underline{n_{\mathrm{D}}}$} \\
\hline & Exp. & Lit. & Exp. & Lit. \\
\hline Methyl pentanoate & 884.78 & $\begin{array}{l}884.66^{c} \\
884.58^{e}\end{array}$ & 1.3952 & $\begin{array}{l}1.3948^{c} \\
1.3947^{e}\end{array}$ \\
\hline Methyl methanoate & 966.28 & $\begin{array}{l}966.8^{b} \\
965.8^{c} \\
966.4^{d} \\
966.18^{e}\end{array}$ & 1.3411 & $\begin{array}{l}1.34074^{b} \\
1.3415^{c} \\
1.3412^{e}\end{array}$ \\
\hline Methanol & 786.40 & $\begin{array}{l}786.79^{a} \\
786.6^{b} \\
786.64^{c, d}\end{array}$ & 1.3261 & $\begin{array}{l}1.3266^{a} \\
1.32640^{b} \\
1.32652^{c, d}\end{array}$ \\
\hline
\end{tabular}

Uncertainties $u$ are: $u(T)= \pm 0.02 \mathrm{~K}, u(n)= \pm 0.0002$, and $u(\rho)= \pm 0.02 \mathrm{~kg} \cdot \mathrm{m}^{-3}$

a Reference [7].

${ }^{b}$ Reference [20].

${ }^{c}$ Reference [24].

${ }^{d}$ Reference [25].

e Reference [26].

\subsection{Apparatus and procedures}

The water content was determined by a Mettler C-20 KarlFisher titrator and a HP-6890N GC from Agilent was used for evaluate the quality of products. Densities of the pure compounds and mixtures were measured with an Anton Paar DMA 60/602 digital densimeter $(\rho \pm 0.02) \mathrm{kg} \cdot \mathrm{m}^{-3}$, maintaining the temperature at $(298 \pm 0.01) \mathrm{K}$ using a 1166D Polyscience thermostatic water-bath. The densimeter was calibrated with water and nonane using a procedure described previously [23]. Densities were used to calculate the excess volumes of binaries $\left[\left(V_{\mathrm{m}}^{\mathrm{E}} \pm 2 \cdot 10^{-9}\right) \mathrm{m}^{3} \cdot \mathrm{mol}^{-1}\right.$; $x \pm 0.0002]$ and ternaries $\left[\left(V_{\mathrm{m}}^{\mathrm{E}} \pm 5 \cdot 10^{-9}\right) \mathrm{m}^{3} \cdot \mathrm{mol}^{-1} ; x \pm 0.0005\right]$. Refractive indices $\left(n_{\mathrm{D}} \pm 0.0002\right)$ of the pure compounds were measured with a 302 Abbe refractometer by Zuzi. The apparatus was maintained at a constant temperature of $(298.15 \pm 0.01) \mathrm{K}$ using a Polyscience 9012 circulating water-bath, and was calibrated with water, assigning as exact value that shown in ref [24]. The mixing enthalpies $\left[\left(H_{\mathrm{m}}^{\mathrm{E}} \pm 1 \%\right) \mathrm{J} \cdot \mathrm{mol}^{-1} ; x \pm 0.0002\right]$ at a temperature of $(298 \pm 0.01) \mathrm{K}$ were measured directly with a MS80D Calvet conduction calorimeter by Setaram. Calibration was carried out by applying a Joule effect provided by an external power source, to simulate analogous thermograms to the mixing process. Correct functioning of the system was checked using the standard mixture of (cyclohexane + hexane) [27].

The working procedure followed to obtain the mixing quantities, $V_{\mathrm{m}}^{\mathrm{E}}$ and $H_{\mathrm{m}}^{\mathrm{E}}$, of the ternaries was analogous to that used in a previous work [8]. By means of successive weighing, solutions $\left(\cong 40 \mathrm{~cm}^{3}\right)$ of known concentrations of (methyl pentanoate (1) + methanol (3)) were prepared. Each solution (considered as a

TABLE 1

Pure compounds specifications.

\begin{tabular}{|c|c|c|c|c|c|}
\hline \multirow[t]{2}{*}{ Compound } & \multirow[t]{2}{*}{ CAS No. } & \multirow[t]{2}{*}{ Supplier } & \multicolumn{2}{|c|}{ Purity w/w\% } & \multirow[t]{2}{*}{ Analytical method } \\
\hline & & & Original & Final & \\
\hline Methyl pentanoate & $624-24-8$ & Aldrich & 98.6 & 99.0 & GC \\
\hline Methyl methanoate & $107-31-3$ & Aldrich & 99.0 & 99.3 & GC \\
\hline Methanol & $67-56-1$ & Aldrich & 99.9 & 99.9 & GC \\
\hline TMS & $75-76-3$ & Aldrich & 99.9 & & GC \\
\hline $\mathrm{Cl}_{3} \mathrm{CD}$ & $865-49-6$ & Aldrich & 99.96 & & GC \\
\hline Water & $7732-18-15$ & & & $<1 \mu S$ & Conductivity meter \\
\hline Nonane & $111-84-2$ & Aldrich & 99.0 & 99.1 & GC \\
\hline
\end{tabular}


TABLE 3

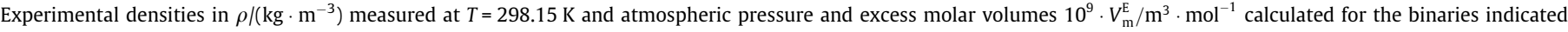
below.

\begin{tabular}{|c|c|c|c|c|c|c|c|c|}
\hline $\mathrm{x}_{1}$ & $\rho / \mathrm{kg} \cdot \mathrm{m}^{-3}$ & $10^{9} \cdot V_{\mathrm{m}}^{\mathrm{E}} / \mathrm{m}^{3} \cdot \mathrm{mol}^{-1}$ & $\mathrm{x}_{1}$ & $\rho / \mathrm{kg} \cdot \mathrm{m}^{-3}$ & $10^{9} \cdot V_{\mathrm{m}}^{\mathrm{E}} / \mathrm{m}^{3} \cdot \mathrm{mol}^{-1}$ & $\mathrm{x}_{1}$ & $\rho / \mathrm{kg} \cdot \mathrm{m}^{-3}$ & $10^{9} \cdot V_{\mathrm{m}}^{\mathrm{E}} / \mathrm{m}^{3} \cdot \mathrm{mol}^{-1}$ \\
\hline \multicolumn{9}{|c|}{ ( $x_{1}$ Methyl pentanoate $+x_{2}$ methyl methanoate) } \\
\hline 0.0000 & 966.28 & 0 & 0.3493 & 919.84 & 294 & 0.7258 & 895.50 & 207 \\
\hline 0.0555 & 956.19 & 75 & 0.4011 & 915.46 & 302 & 0.7765 & 893.24 & 171 \\
\hline 0.1040 & 948.47 & 129 & 0.4572 & 911.17 & 302 & 0.8360 & 890.80 & 123 \\
\hline 0.1464 & 942.39 & 170 & 0.5000 & 908.17 & 299 & 0.9031 & 888.23 & 70 \\
\hline 0.2093 & 934.27 & 229 & 0.5539 & 904.69 & 288 & 1.0000 & 884.78 & 0 \\
\hline 0.2537 & 929.22 & 257 & 0.6081 & 901.55 & 264 & & & \\
\hline 0.3106 & 923.46 & 279 & 0.6522 & 899.15 & 246 & & & \\
\hline \multicolumn{9}{|c|}{ ( $x_{1}$ Methyl pentanoate $+x_{2}$ methanol) } \\
\hline 0.0000 & 786.40 & 0 & 0.2480 & 837.51 & -32 & 0.7472 & 875.67 & -28 \\
\hline 0.0235 & 793.56 & -4 & 0.3040 & 844.36 & -36 & 0.7884 & 877.42 & -25 \\
\hline 0.0620 & 803.85 & -10 & 0.3501 & 849.28 & -39 & 0.7982 & 877.81 & -23 \\
\hline 0.0741 & 806.78 & -12 & 0.4499 & 858.16 & -41 & 0.8786 & 880.85 & -15 \\
\hline 0.1314 & 818.95 & -19 & 0.5121 & 862.75 & -41 & 0.9630 & 883.66 & -4 \\
\hline 0.1512 & 822.61 & -22 & 0.6073 & 868.69 & -38 & 1.0000 & 884.78 & 0 \\
\hline 0.2017 & 830.95 & -28 & 0.6865 & 872.86 & -34 & & & \\
\hline \multicolumn{9}{|c|}{ ( $x_{1}$ Methyl methanoate $+x_{2}$ methanol) } \\
\hline 0.0000 & 786.40 & 0 & 0.3219 & 863.26 & -72 & 0.7815 & 939.62 & -73 \\
\hline 0.0337 & 795.73 & -12 & 0.3906 & 876.73 & -79 & 0.8533 & 949.01 & -59 \\
\hline 0.0833 & 808.80 & -27 & 0.4946 & 895.61 & -85 & 0.8968 & 954.39 & -46 \\
\hline 0.1557 & 826.74 & -46 & 0.5416 & 903.58 & -87 & 0.8968 & 954.39 & -46 \\
\hline 0.1900 & 834.77 & -52 & 0.6467 & 920.31 & -87 & 0.9357 & 959.02 & -32 \\
\hline 0.2499 & 848.14 & -62 & 0.7271 & 932.10 & -81 & 1.0000 & 966.28 & 0 \\
\hline
\end{tabular}

Uncertainties $u$ are: $u(T)= \pm 0.02 \mathrm{~K}, u(\rho)= \pm 0.02 \mathrm{~kg} \cdot \mathrm{m}^{-3}, u(x)= \pm 0.0002, u\left(10^{9} \cdot V_{\mathrm{m}}^{\mathrm{E}}\right)= \pm 2 \mathrm{~m}^{-3} \cdot \mathrm{mol}^{-1}$.

TABLE 4

Experimental excess molar enthalpies $H_{\mathrm{m}}^{\mathrm{E}} / \mathrm{J} \cdot \mathrm{mol}^{-1}$ measured directly at $T=298.15 \mathrm{~K}$ and atmospheric pressure for the binaries indicated below.

\begin{tabular}{|c|c|c|c|c|c|}
\hline $\mathrm{x}_{1}$ & $H_{\mathrm{m}}^{\mathrm{E}} / \mathrm{J} \cdot \mathrm{mol}^{-1}$ & $\mathrm{x}_{1}$ & $H_{\mathrm{m}}^{\mathrm{E}} / \mathrm{J} \cdot \mathrm{mol}^{-1}$ & $\mathrm{x}_{1}$ & $H_{\mathrm{m}}^{\mathrm{E}} / \mathrm{J} \cdot \mathrm{mol}^{-1}$ \\
\hline \multicolumn{6}{|c|}{ ( $x_{1}$ Methyl pentanoate $+x_{2}$ methyl methanoate) } \\
\hline 0,0272 & 59 & 0,2533 & 379 & 0,5232 & 409 \\
\hline 0,0583 & 112 & 0,2946 & 401 & 0,6056 & 366 \\
\hline 0,0932 & 171 & 0,3096 & 413 & 0,6943 & 304 \\
\hline 0,1292 & 230 & 0,3486 & 422 & 0,7968 & 219 \\
\hline 0,1720 & 291 & 0,3982 & 431 & 0,8656 & 145 \\
\hline 0,2104 & 340 & 0,4522 & 431 & 0,9300 & 84 \\
\hline \multicolumn{6}{|c|}{$\left(x_{1}\right.$ Methyl pentanoate $+x_{2}$ methanol) } \\
\hline 0,0244 & 83 & 0,2640 & 736 & 0,5081 & 1091 \\
\hline 0,0512 & 169 & 0,2993 & 819 & 0,5867 & 1095 \\
\hline 0,0839 & 277 & 0,3336 & 876 & 0,6887 & 1006 \\
\hline 0,1195 & 383 & 0,3670 & 921 & 0,7931 & 812 \\
\hline 0,1562 & 485 & 0,3861 & 947 & 0,8868 & 533 \\
\hline 0,1920 & 578 & 0,4156 & 990 & 0,9570 & 240 \\
\hline 0,2279 & 665 & 0,4625 & 1053 & & \\
\hline \multicolumn{6}{|c|}{ ( $x_{1}$ Methyl methanoate $+x_{2}$ methanol) } \\
\hline 0,0200 & 75 & 0,3086 & 914 & 0,5783 & 1196 \\
\hline 0,0487 & 179 & 0,3501 & 987 & 0,6460 & 1178 \\
\hline 0,0833 & 311 & 0,3644 & 1010 & 0,7178 & 1105 \\
\hline 0,1225 & 441 & 0,3943 & 1054 & 0,7842 & 984 \\
\hline 0,1670 & 577 & 0,4077 & 1074 & 0,8517 & 808 \\
\hline 0,2135 & 703 & 0,4572 & 1131 & 0,9098 & 584 \\
\hline 0,2613 & 817 & 0,5127 & 1179 & 0,9505 & 339 \\
\hline
\end{tabular}

Uncertainties $u$ are: $u(T)= \pm 0.01 \mathrm{~K}, u(x)= \pm 0.0002$, and $u_{r}\left(H_{\mathrm{m}}^{\mathrm{E}}\right)= \pm 0.01$.

pseudocomponent) was then used to determine the excess property, $V_{\mathrm{m}}^{\mathrm{E}}$ or $H_{\mathrm{m}}^{\mathrm{E}}$, of a pseudobinary system, now using the methyl methanoate as a second component. In this way, series of data are obtained whose compositions obeying a constant ratio of $x_{1} / x_{3}$.

For the structural analysis of the pure compounds and solutions, a $300 \mathrm{MHz}$ Bruker ${ }^{1} \mathrm{H}$ NMR spectrometer was employed to take measurements at $T=293 \mathrm{~K}$, using $\mathrm{Cl}_{3} \mathrm{CD}$ (see table 1 ) in concentric capillaries to achieve the lock. Chemical shifts were measured in relation to the signal of TMS $(\delta=0)$ (see table 1 ), dissolved in $\mathrm{Cl}_{3} \mathrm{CD}$.

\section{Presentation and correlation of experimental data}

Table 3 shows the experimental values of $\left(x_{1}, \rho, V_{\mathrm{m}}^{\mathrm{E}}\right)$ at $T=298.15 \mathrm{~K}$ for the binaries (methyl pentanoate (1) + methanol (3)), (methyl methanoate (2) + methanol (3)), and (methyl pentanoate (1) + methyl methanoate (2)). The empirical formulation is given for: $\mathrm{H}_{2 \mathrm{u}-1} \mathrm{C}_{\mathrm{u}} \mathrm{OOCH}_{3}(\mathrm{u}=1,5)$ for the methyl esters and $\mathrm{CH}_{3}(\mathrm{OH})$ for methanol. Table 4 shows the corresponding values of $\left(x_{1}, H_{\mathrm{m}}^{\mathrm{E}}\right)$ for the same binaries. Values of the mixing properties are recorded graphically in figure $1(\mathrm{a})$ and (b). Both data sets were correlated by a polynomial equation as a function of the composition of one of the compounds of the studied system. If the referenced compound is the first-mentioned, the equation is:

$Y_{\mathrm{m}}^{\mathrm{E}}=z_{1} z_{2} \sum_{\mathrm{i}=0}^{2} A_{\mathrm{i}} z_{1}^{\mathrm{i}}=z_{1}\left(1-z_{1}\right)\left(A_{0}+A_{1} z_{1}+A_{2} z_{1}^{2}+A_{3} z_{1}^{3}\right)$,

where

$z_{\mathrm{i}}=\frac{v_{\mathrm{i}} x_{\mathrm{i}}}{\sum_{\mathrm{j}=1}^{\mathrm{n}} v_{\mathrm{j}} x_{\mathrm{j}}}=\frac{k^{\mathrm{i}-1} x_{\mathrm{i}}}{x_{\mathrm{i}}+\sum_{\mathrm{i}=2}^{\mathrm{n}} k^{\mathrm{i}-1} x_{\mathrm{i}}}$

corresponding to the variable called the active fraction of the property considered. For the moment, no single significance is assigned to the " $k$ " ratio, as its meaning depends on the property to which it is applied, although this parameter is known to be associated with the nature of the compounds in solution. Hence, when equation (1) is applied to volumes, this ratio between two compounds $i-j$ is identified by the quotient of molar volumes of the substances: $k^{\mathrm{j}-\mathrm{i}} \equiv k_{\mathrm{v}}^{\mathrm{j}-\mathrm{i}}=v_{\mathrm{j}}^{\mathrm{o}} / \nu_{\mathrm{i}}^{\mathrm{o}}$. The parameters $k^{\mathrm{j}-\mathrm{i}}$ of the three binaries are not independent of each other, and obey the relationship: $k^{3-2} k^{2-1}=k^{3-1}$, regardless of the property under study.

Correlation of $H_{\mathrm{m}}^{\mathrm{E}}$ values for the binaries is also carried out with equation (1), but now the $v_{\text {i }}$ parameters of equation (2) are associated with a characteristic of the compounds that produce the energetic effects in the mixing process. With this hypothesis, enthalpic results are largely a consequence of the contact surfaces of the molecules. That is, to advance the theoretical version of the model (equation (1)) is particularly interesting to define the meaning of 

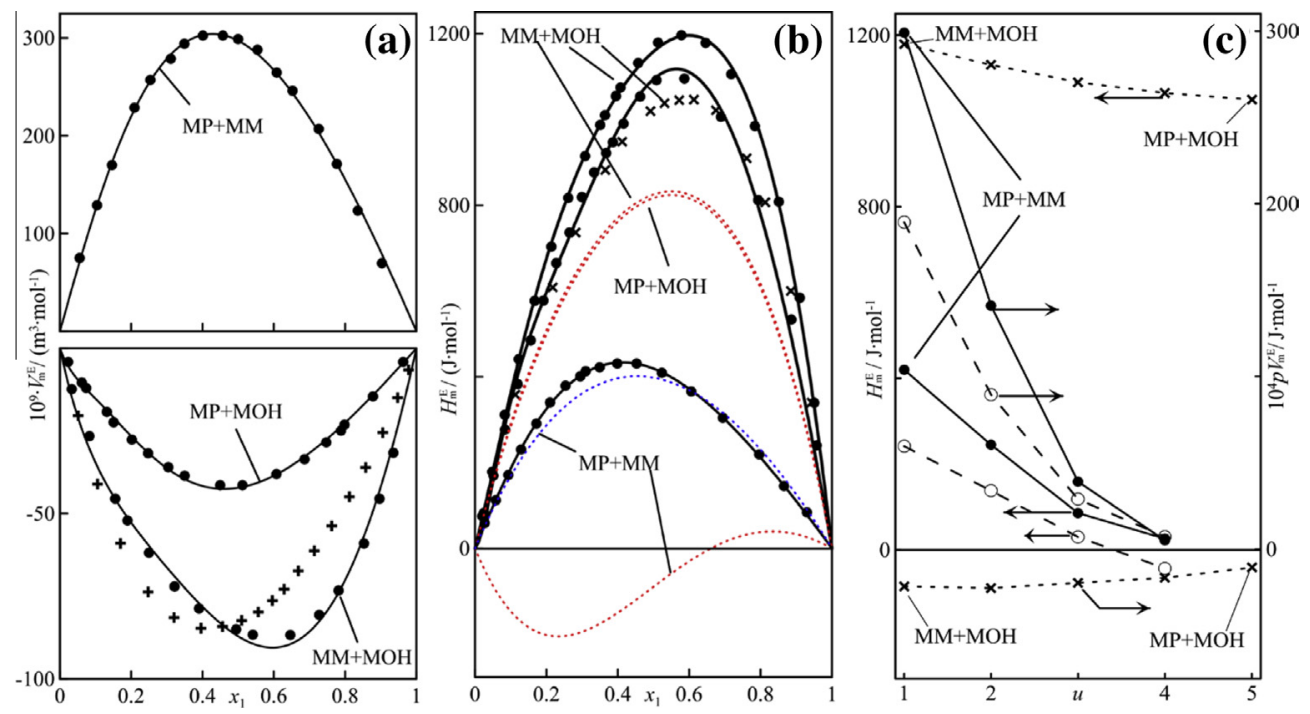

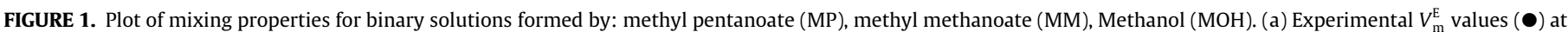

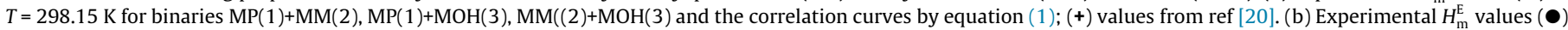

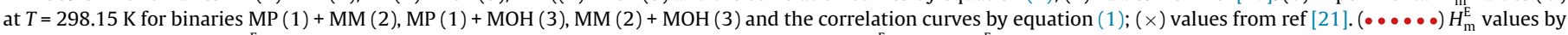

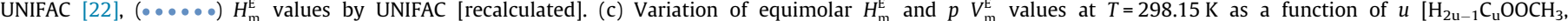

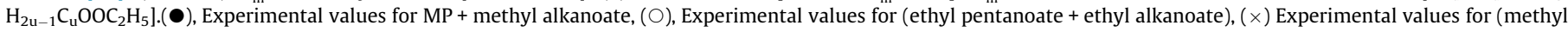
alkanoate $+\mathrm{MOH})$.

TABLE 5

Coefficients $A_{\mathrm{i}}$ and standard deviations $s\left(Y_{\mathrm{m}}^{\mathrm{E}}\right)$ obtained for equation (1) in the correlation of excess molar properties obtained at $T=298.15 \mathrm{~K}$ and atmospheric pressure of the binaries formed by two methyl esters and methanol.

\begin{tabular}{|c|c|c|c|c|c|c|}
\hline Binary system & $A_{0}$ & $A_{1}$ & $A_{2}$ & $A_{3}$ & $k^{\mathrm{j}-\mathrm{i}}$ & $s\left(Y_{\mathrm{m}}^{\mathrm{E}}\right)$ \\
\hline & \multicolumn{6}{|c|}{$Y_{\mathrm{m}}^{\mathrm{E}}=10^{9} \cdot V_{\mathrm{m}}^{\mathrm{E}} / \mathrm{m}^{3} \cdot \mathrm{mol}^{-1}$} \\
\hline $\begin{array}{l}\text { (Methyl pentanoate } \\
(1)+\text { methyl } \\
\text { methanoate }(2))\end{array}$ & 617 & 951 & 218 & 0 & 0.473 & 4 \\
\hline $\begin{array}{l}\text { (Methyl pentanoate } \\
\quad(1)+\text { methanol (3)) }\end{array}$ & -93 & 181 & -479 & 0 & 0.310 & 1 \\
\hline \multirow[t]{2}{*}{$\begin{array}{l}\text { (Methyl methanoate } \\
(2)+\text { methanol (3)) }\end{array}$} & -333 & 506 & -923 & 0 & 0.656 & 2 \\
\hline & \multicolumn{3}{|c|}{$Y_{\mathrm{m}}^{\mathrm{E}}=H_{\mathrm{m}}^{\mathrm{E}} / J \cdot \mathrm{mol}^{-1}$} & & & \\
\hline $\begin{array}{l}\text { (Methyl pentanoate } \\
(1)+\text { methyl } \\
\text { methanoate }(2))\end{array}$ & 1006 & 1478 & -248 & 0 & 0.506 & 3 \\
\hline $\begin{array}{l}\text { (Methyl pentanoate } \\
\quad(1)+\text { methanol (3)) }\end{array}$ & 234 & 11839 & -27845 & 29462 & 0.352 & 20 \\
\hline $\begin{array}{l}\text { (Methyl methanoate } \\
(2)+\text { methanol (3)) }\end{array}$ & 2339 & 6590 & -12460 & 14111 & 0.695 & 11 \\
\hline
\end{tabular}

the ratio $k^{\mathrm{j}-\mathrm{i}}$ and fix for the property under study. One method that can be used is to calculate the parameter $k^{\mathrm{j}-\mathrm{i}}$ by considering it to be the quotient of normalized values of Van der Waals volumes for the case of $k_{\mathrm{v}}^{\mathrm{j}-\mathrm{i}}$ mentioned previously, and of surfaces for the case of the own parameter of $H_{\mathrm{m}}^{\mathrm{E}}, k_{\mathrm{h}}^{\mathrm{j}-\mathrm{i}}$. The simplest approach is to propose that the molecule generates a spherical envelope in its Brownian motion, resulting in a geometric ratio of surface/volume. Therefore, it is useful to identify the ratio, for example, with the parameters calculated by Bondi's method [28], which, in turn, are normalized values corresponding to the Van der Waals surface and volume, see table S1 (supplementary material), as shown below:

$$
\begin{aligned}
& {\left[\frac{\text { surface }}{\text { volume }}\right]_{\text {geometric }}=\left[\frac{\text { surface }}{\text { volume }}\right]_{\text {theoretical }},} \\
& {\left[\frac{S_{i}}{V_{\mathrm{i}}}\right]_{\text {geometric }}=\left[\frac{q_{i}}{\left(r_{\mathrm{i}}\right)^{2 / 3}}\right]_{\text {theoretical }} .}
\end{aligned}
$$

For two substances $\mathrm{i}-\mathrm{j}$ :

$$
k_{\mathrm{h}}^{\mathrm{j}-\mathrm{i}}=\frac{S_{\mathrm{i}}}{S_{\mathrm{j}}}=\frac{q_{\mathrm{i}}}{q_{\mathrm{j}}} \cdot\left(\frac{r_{\mathrm{j}} V_{\mathrm{i}}}{r_{\mathrm{i}} V_{\mathrm{j}}}\right)^{2 / 3}=k_{\mathrm{q}}^{\mathrm{j}-\mathrm{i}}\left(\frac{k_{\mathrm{v}}^{\mathrm{j}-\mathrm{i}}}{k_{\mathrm{r}}^{\mathrm{j}-\mathrm{i}}}\right)^{2 / 3}
$$

this corresponds to a correction of theoretical ratios $k_{\mathrm{q}}$ and $k_{\mathrm{r}}$, since these parameters themselves do not take into account changes in temperature, nor do they vary with the regioisomers. Another method proposed in the literature to obtain these ratios directly is that suggested by Connolly $[29,30]$, in which molecular surface and volume are calculated independently. Table S1 records the values obtained for pure components and the $k^{\mathrm{j}-\mathrm{i}}$ values for the binaries studied, showing the numerical similarity among the values obtained by different methods. The methodology proposed by us above presents minor differences with the Bondi parameters method, with the advantage that the temperature variations and differences between regioisomers are considered.

In the treatment of the ternary, a previous consideration is taken into account, that the values of $k_{\mathrm{v}}^{\mathrm{j}-\mathrm{i}}$ and $k_{\mathrm{h}}^{\mathrm{j}-\mathrm{i}}$ for the three binaries are not independent, in each property obeying the relationships: $k_{\mathrm{v}}^{3-2} k_{\mathrm{v}}^{2-1}=k_{\mathrm{v}}^{3-1}$ and $k_{\mathrm{h}}^{3-2} k_{\mathrm{h}}^{2-1}=k_{\mathrm{h}}^{3-1}$.

Experimental data of the binaries are correlated with equation (1), using a non-linear regression procedure that optimizes the following objective function $(O F)$ :

$O F=s\left(Y_{\mathrm{m}, \mathrm{i}}^{\mathrm{E}}\right)=\left[\sum_{\mathrm{i}}\left(Y_{\mathrm{m}, \mathrm{i}, \exp }^{\mathrm{E}}-Y_{\mathrm{m}, \mathrm{i}, \mathrm{cal}}^{\mathrm{E}}\right)^{2} /(N-1)\right]^{0.5}$

To obtain an expression that is applicable to the ternaries, the origins of equation (1) must be considered. This corresponds to a generalization for multicomponent systems, comprised by $n$ substances, which generate a recurrent expression that condenses in:

$Y_{\mathrm{m}, \mathrm{i}}^{\mathrm{E}}=\sum Y_{\mathrm{m}, n-1, N}^{\mathrm{E}\left(i_{1}-i_{2}-i_{3} \cdots-i_{n-1}\right)}+T_{n} \cdot P_{N}$,

where $N$ is the order of the molecular interaction considered and the term $Y_{\mathrm{m}, n-1, N}^{\mathrm{E}\left(i_{1}-i_{2}-\cdots-i_{n-1}\right)}$ represents the partial contribution of the excess property $Y_{\mathrm{m}}^{\mathrm{E}}$ owing to the interaction of $(n-1)$ different species to a maximum order of interaction $N$. On the contrary, each 
TABLE 6

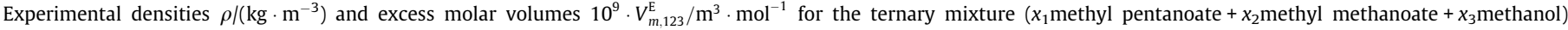
obtained at $T=298.15 \mathrm{~K}$ and atmospheric pressure.

\begin{tabular}{|c|c|c|c|c|c|c|c|}
\hline $\mathrm{x}_{1}$ & $\mathrm{x}_{2}$ & $\rho / \mathrm{kg} \cdot \mathrm{m}^{-3}$ & $10^{9} \cdot V_{m, 123}^{\mathrm{E}} / \mathrm{m}^{3} \cdot \mathrm{mol}^{-1}$ & $\mathrm{x}_{1}$ & $\mathrm{x}_{2}$ & $\rho / \mathrm{kg} \cdot \mathrm{m}^{-3}$ & $10^{9} \cdot V_{m, 123}^{\mathrm{E}} / \mathrm{m}^{3} \cdot \mathrm{mol}^{-1}$ \\
\hline \multicolumn{8}{|c|}{$x_{1}^{\prime}=0.2442$} \\
\hline 0.0000 & 1.0000 & 966.28 & 0 & 0.0949 & 0.6112 & 915.09 & 28 \\
\hline 0.0097 & 0.9605 & 961.26 & -11 & 0.1189 & 0.5130 & 902.25 & 35 \\
\hline 0.0190 & 0.9224 & 956.25 & -9 & 0.1417 & 0.4194 & 890.13 & 35 \\
\hline 0.0352 & 0.8557 & 947.43 & -3 & 0.1560 & 0.3609 & 882.62 & 31 \\
\hline 0.0480 & 0.8035 & 940.51 & 3 & 0.1679 & 0.3122 & 876.39 & 26 \\
\hline 0.0595 & 0.7561 & 934.22 & 11 & 0.1890 & 0.2261 & 865.47 & 13 \\
\hline 0.0716 & 0.7069 & 927.72 & 16 & 0.2055 & 0.1583 & 856.93 & -2 \\
\hline 0.0827 & 0.6611 & 921.67 & 22 & 0.2177 & 0.1083 & 850.65 & -13 \\
\hline \multicolumn{8}{|c|}{$x_{1}^{\prime}=0.4031$} \\
\hline 0.0000 & 1.0000 & 966.28 & 0 & 0.2057 & 0.4898 & 901.41 & 109 \\
\hline 0.0209 & 0.9481 & 958.88 & 15 & 0.2182 & 0.4586 & 898.04 & 106 \\
\hline 0.0418 & 0.8963 & 951.68 & 31 & 0.2597 & 0.3558 & 887.35 & 86 \\
\hline 0.0585 & 0.8548 & 945.98 & 47 & 0.3020 & 0.2508 & 877.03 & 54 \\
\hline 0.0769 & 0.8093 & 939.94 & 60 & 0.3225 & 0.1999 & 872.27 & 31 \\
\hline 0.1018 & 0.7475 & 931.91 & 79 & 0.3436 & 0.1476 & 867.43 & 11 \\
\hline 0.1121 & 0.7218 & 928.62 & 88 & 0.3570 & 0.1143 & 864.43 & -4 \\
\hline 0.1451 & 0.6401 & 918.60 & 104 & 0.3788 & 0.0603 & 859.62 & -26 \\
\hline 0.1802 & 0.5529 & 908.44 & 111 & & & & \\
\hline \multicolumn{8}{|c|}{$x_{1}^{\prime}=0.5922$} \\
\hline 0.0000 & 1.0000 & 966.28 & 0 & 0.3563 & 0.3983 & 895.80 & 151 \\
\hline 0.0320 & 0.9460 & 957.92 & 32 & 0.3806 & 0.3573 & 892.49 & 135 \\
\hline 0.0630 & 0.8936 & 950.16 & 68 & 0.4481 & 0.2433 & 883.90 & 81 \\
\hline 0.0980 & 0.8345 & 941.91 & 107 & 0.4179 & 0.2943 & 887.60 & 110 \\
\hline 0.1213 & 0.7952 & 936.81 & 124 & 0.4692 & 0.2077 & 881.36 & 64 \\
\hline 0.1456 & 0.7542 & 931.64 & 145 & 0.4909 & 0.1710 & 878.87 & 41 \\
\hline 0.1793 & 0.6972 & 924.89 & 165 & 0.5292 & 0.1064 & 874.57 & 8 \\
\hline 0.2438 & 0.5883 & 913.16 & 182 & 0.5521 & 0.0677 & 872.10 & -14 \\
\hline 0.2970 & 0.4985 & 904.50 & 178 & 0.5610 & 0.0527 & 871.23 & -30 \\
\hline 0.3199 & 0.4598 & 901.04 & 169 & & & & \\
\hline \multicolumn{8}{|c|}{$x_{1}^{\prime}=0.7818$} \\
\hline 0.0000 & 1.0000 & 966.28 & 0 & 0.3973 & 0.4918 & 905.54 & 260 \\
\hline 0.0506 & 0.9353 & 955.31 & 75 & 0.4191 & 0.4639 & 903.40 & 255 \\
\hline 0.0785 & 0.8996 & 949.82 & 110 & 0.4848 & 0.3799 & 897.52 & 223 \\
\hline 0.1181 & 0.8489 & 942.53 & 157 & 0.5488 & 0.2980 & 892.37 & 180 \\
\hline 0.1753 & 0.7758 & 933.10 & 209 & 0.5893 & 0.2462 & 889.40 & 145 \\
\hline 0.2286 & 0.7076 & 925.27 & 246 & 0.6185 & 0.2089 & 887.35 & 120 \\
\hline 0.2836 & 0.6372 & 918.11 & 263 & 0.6698 & 0.1433 & 884.00 & 66 \\
\hline 0.3239 & 0.5857 & 913.33 & 269 & 0.7028 & 0.1010 & 881.92 & 34 \\
\hline \multicolumn{8}{|c|}{$x_{1}^{\prime}=0.8879$} \\
\hline 0.0000 & 1.0000 & 966.28 & 0 & 0.4309 & 0.5092 & 907.81 & 277 \\
\hline 0.0473 & 0.9461 & 956.79 & 68 & 0.4743 & 0.4597 & 904.27 & 266 \\
\hline 0.0928 & 0.8943 & 948.38 & 142 & 0.5584 & 0.3639 & 898.15 & 230 \\
\hline 0.1403 & 0.8402 & 940.79 & 188 & 0.6482 & 0.2616 & 892.48 & 173 \\
\hline 0.2139 & 0.7564 & 930.50 & 240 & 0.6933 & 0.2103 & 889.95 & 135 \\
\hline 0.2638 & 0.6995 & 924.38 & 264 & 0.7383 & 0.1590 & 887.59 & 92 \\
\hline 0.3317 & 0.6222 & 916.97 & 283 & 0.7692 & 0.1238 & 886.03 & 64 \\
\hline 0.3953 & 0.5497 & 910.90 & 282 & 0.8152 & 0.0714 & 883.80 & 24 \\
\hline
\end{tabular}

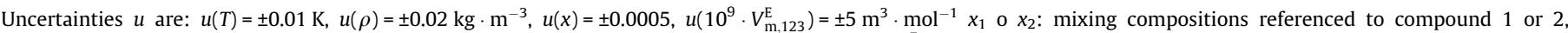
respectively. $x_{1}^{\prime}$ : composition of compound 1 in the pseudobinary. $\rho$ : density of ternary mixture. $V_{\mathrm{m}, 123}^{\mathrm{E}}$ : excess volumes for ternary mixture.

of these excess quantities can be reduced, in turn, to the $Y_{\mathrm{m}, n-1, N}^{\mathrm{E}}$ and reach the corresponding binary interactions. The term $T_{n} \cdot P_{N}$ essentially represents the multiple product of the active fractions of the $n$ substances and a polynomial, for which the degree is determined by $N$. The general form of $T_{n}$, expressed in terms of the active fractions $z_{\mathrm{i}}$, using a generalized form of expression (2), becomes:

$T_{n}=\frac{\prod_{i=2}^{n} k_{i 1} \prod_{i=1}^{n} x_{i}}{\left[x_{1}+\sum_{i=2}^{n} k_{i 1} x_{i}\right]^{n}}$

for the case that concerns us here, with $n=3$ an interactional order of 4 or 5 appears to be sufficient. By considering the terms corresponding to the $Y_{m, 2.5}^{\mathrm{E}(i-j)}$ of equation (6), it is necessary to take into account the contributions due to the possible combinations $C^{*}(3,2)$ of three substances taken two by two, $\mathrm{i}-\mathrm{j}$, using interactions of up to the fifth-order to reproduce the tendency of the properties obtained by experimentation. By applying model (6), and the term $T_{\mathrm{n}}$ of the equation (7), to the case of a ternary with the specified number of interactions, we obtain the following expression:

$$
\begin{aligned}
Y_{\mathrm{m}, 2,5}^{\mathrm{E}}= & \sum Y_{\mathrm{m}, 2,5}^{\mathrm{E}\left(i_{1}-i_{2}-i_{3} \ldots-i_{n-1}\right)}+z_{1} z_{2} z_{3}\left(C_{0}+C_{1} z_{1}+C_{2} z_{2}+C_{3} z_{1}^{2}\right. \\
& \left.+C_{4} z_{2}^{2}+C_{5} z_{1} z_{2}\right)
\end{aligned}
$$

Optimization of the $C_{\mathrm{i}}$ parameters is carried out by a non-linear procedure, analogous to that used in adjustment of the binaries, and using the same $O F$ as that used for the binaries. In this work it was necessary to consider a high degree of interaction (fifth order) due to the complex distribution of experimental points 

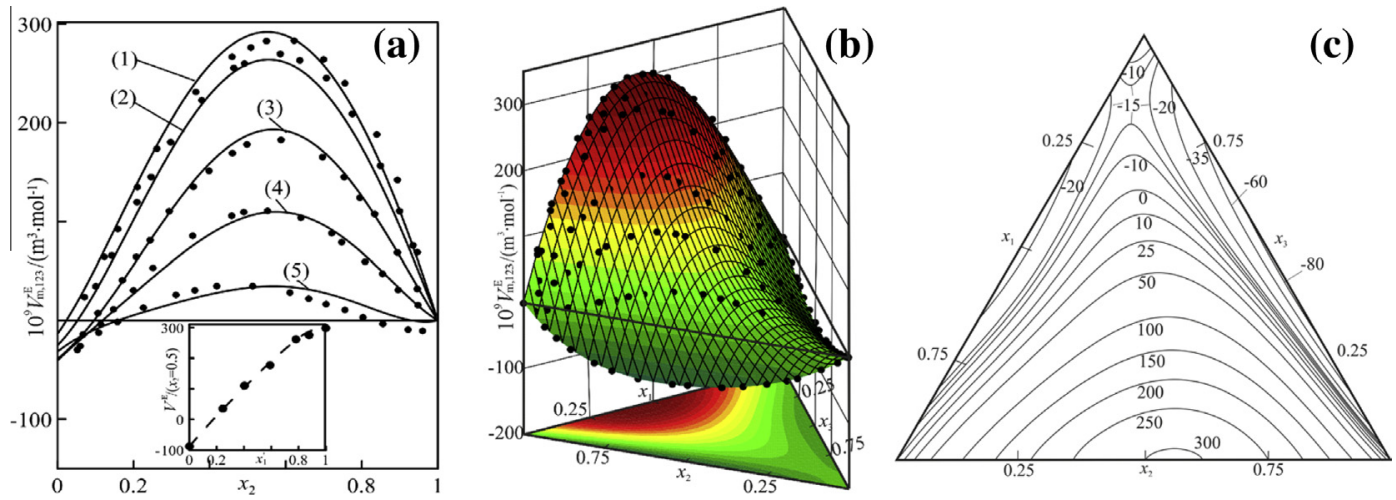

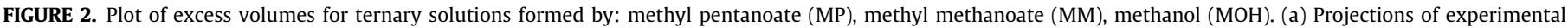

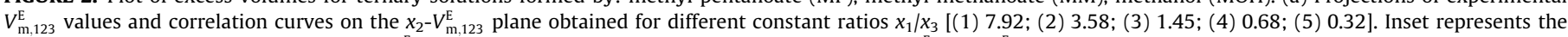

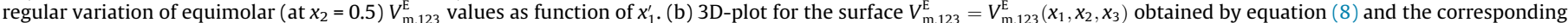

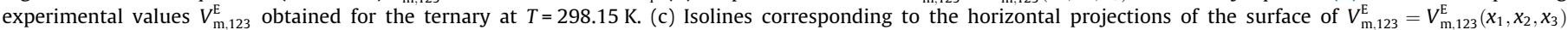
represented in (b) for constant values of $V_{\mathrm{m}, 123}^{\mathrm{E}}$ which are indicated by the labels in $10^{9} \cdot \mathrm{m}^{3} \cdot \mathrm{mol}^{-1}$.

TABLE 7

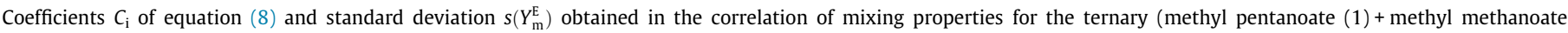
(2) + methanol (3)) at $T=298.15 \mathrm{~K}$.

\begin{tabular}{|c|c|c|c|c|c|c|c|c|c|}
\hline Property & $k^{2-1}$ & $k^{3-1}$ & $C_{0}$ & $C_{1}$ & $C_{2}$ & $C_{3}$ & $C_{4}$ & $C_{5}$ & $s\left(Y_{\mathrm{m}}^{\mathrm{E}}\right)$ \\
\hline $10^{9} \cdot V_{\mathrm{m}, 123}^{\mathrm{E}}$ & 0.473 & 0.310 & 1674 & -46388 & -52421 & 23604 & 34995 & 76439 & 10 \\
\hline$H_{\mathrm{m}, 123}^{\mathrm{E}}$ & 0.506 & 0.352 & 35613 & -123531 & -85039 & 142709 & 96878 & 180734 & 25 \\
\hline
\end{tabular}

resulting from different interactional effects. In previous work, with solutions containing esters and alkanes, an interaction degree of fourth order was considered sufficient.

\subsection{Excess volumes}

Representations of $\left(x, V_{\mathrm{m}}^{\mathrm{E}}\right)$ data by curves corresponding to the binaries in study, obtained with equation (1) and the coefficients resulting from applying the afore-mentioned procedure, table 5 , are shown, respectively, in figure 1(a). Regarding the volumetric analysis, it is noteworthy that solutions of (methyl pentanoate (1) + methyl methanoate (2)) present expansive effects $V_{\mathrm{m}}^{\mathrm{E}}>0$, which are three times higher in absolute value than those of (methyl methanoate (2) + methanol (3)) and six times higher than those of (methyl pentanoate (1) + methanol (3)), see figure 1(c). The appearance of weak interactions, see also enthalpic results, together with steric impediments owing to the size differences between the hydrocarbon chains of the two esters, are reflected in higher volumetric expansions. By contrast, the volumetric effects of the binaries (methyl esters + methanol) give rise to contractions, with $V_{\mathrm{m}}^{\mathrm{E}}<0$, which increase (decrease in absolute value) with the alkanolic chain length of ester, being $\left(d V_{\mathrm{m}}^{\mathrm{E}} / d u\right)_{\mathrm{p}, T}>0$. These observations suggest the presence of molecular aggregates in the systems chosen. A study was found in the literature [20] for the system (methyl methanoate (2)+ methanol (3)) at $T=298.15 \mathrm{~K}$, for which the $V_{\mathrm{m}}^{\mathrm{E}}$ data are represented in figure $1(\mathrm{a})$. In the comparison, it can be observed that our values are clearly asymmetrical to those reported by Polak and Lu, although the correlation curve in their paper is quite similar to ours; this would suggest that the molar fraction of the data presented by these authors is incorrect.

The densities of the ternaries (methyl pentanoate (1) + methyl methanoate (2) + methanol (3)) were measured as described in Section 2.2. Binary mixtures of the methyl methanoate with 5 pseudocompounds are produced by synthetically mixing the two remaining products at predetermined compositions $x_{1}^{\prime}$. Table 6 collects the direct experimental data $\left(x_{1}, x_{2}, \rho\right)$ and the calculated values of $V_{\mathrm{m}, 123}^{\mathrm{E}}$. Slight volumetric contractions are observed in the areas corresponding to low ester composition, arising from the reduction in $V_{\mathrm{m}}^{\mathrm{E}}$ values resulting in the mixed of the two binaries of (methyl alkanoate + methanol), see figure 2(a). The inset figure represents the change in $V_{\mathrm{m}}^{\mathrm{E}(2-1,3)}$ (at $x_{2}=0.5$ ) as a function of the composition of the five pseudobinaries $x_{1}^{\prime}$, with a quasi-linear relation. This variation is justified by the relative increase in methyl pentanoate in the ternary solution.

The mathematical treatment of volumes in the ternary was done by applying equation (8). The $C_{\mathrm{i}}$ coefficients are shown in table 7 , together with the standard deviations, $O F$ defined by equation (5). The surface $V_{\mathrm{m}}^{\mathrm{E}}=V_{\mathrm{m}}^{\mathrm{E}}\left(x_{1}, x_{2}, x_{3}\right)$ generated by equations (1) and (8), using the $k_{v}^{\mathrm{j}-\mathrm{i}}$ of the corresponding $\mathrm{i}-\mathrm{j}$ pair, is represented in 3D in figure 2(b). The correlation curve shown in Figure 2(a) represents the projection of this surface on the plane $x_{2}-V_{\mathrm{m}, 123}^{\mathrm{E}}$. Figure 2(c) shows the isolines of different $V_{\mathrm{m} .123}^{\mathrm{E}}$ projected on the compositions-plane. It can be observed that this amount does not increase monotonously as the composition of methanol in the solution diminishes. There is a local minimum in the interior of the surface at values around $x_{1} \approx x_{2} \approx 0.1$ for both esters, and a high methanol concentration, shown by a confluence of level curves at the specified composition. As mentioned previously, there are contractive effects in the regions close to the binaries of methyl esters with methanol, in the superior vertex of the triangular representation of figure 2(c).

\subsection{Excess enthalpies}

Experimental values of $\left(x_{1}, H_{\mathrm{m}}^{\mathrm{E}}\right)$ for the three binaries studied here, measured at $T=298.15 \mathrm{~K}$, are recorded in table 4 and their representations are shown in figure 1 (b). All the processes are 
TABLE 8

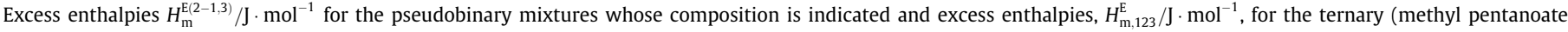
(1) + methyl methanoate (2) + methanol (3)) measured at $T=298.15 \mathrm{~K}$ and atmospheric pressure.

\begin{tabular}{|c|c|c|c|c|c|c|c|}
\hline $\mathrm{x}_{1}$ & $\mathrm{x}_{2}$ & $H_{\mathrm{m}}^{\mathrm{E}(2-1,3)} / \mathrm{J} \cdot \mathrm{mol}^{-1}$ & $H_{\mathrm{m}, 123}^{\mathrm{E}} / \mathrm{J} \cdot \mathrm{mol}^{-1}$ & $\mathrm{x}_{1}$ & $\mathrm{x}_{2}$ & $H_{\mathrm{m}}^{\mathrm{E}(2-1,3)} / \mathrm{J} \cdot \mathrm{mol}^{-1}$ & $H_{\mathrm{m}, 123}^{\mathrm{E}} / \mathrm{J} \cdot \mathrm{mol}^{-1}$ \\
\hline \multicolumn{8}{|c|}{$x_{1}^{\prime}=0.2231$} \\
\hline 0.0335 & 0.8498 & 647 & 750 & 0.0925 & 0.5855 & 1069 & 1353 \\
\hline 0.0343 & 0.8463 & 695 & 800 & 0.1068 & 0.5214 & 1046 & 1373 \\
\hline 0.0377 & 0.8312 & 746 & 861 & 0.1232 & 0.4480 & 978 & 1356 \\
\hline 0.0416 & 0.8135 & 806 & 934 & 0.1387 & 0.3785 & 876 & 1301 \\
\hline 0.0469 & 0.7900 & 868 & 1012 & 0.1555 & 0.3032 & 741 & 1218 \\
\hline 0.0532 & 0.7618 & 928 & 1091 & 0.1730 & 0.2249 & 583 & 1113 \\
\hline 0.0606 & 0.7286 & 983 & 1169 & 0.1900 & 0.1488 & 376 & 958 \\
\hline 0.0693 & 0.6898 & 1033 & 1245 & 0.2056 & 0.0788 & 172 & 802 \\
\hline 0.0799 & 0.6421 & 1063 & 1308 & & & & \\
\hline \multicolumn{8}{|c|}{$x_{1}^{\prime}=0.3631$} \\
\hline 0.0804 & 0.7786 & 736 & 943 & 0.2042 & 0.4377 & 858 & 1383 \\
\hline 0.0881 & 0.7574 & 781 & 1008 & 0.2281 & 0.3719 & 788 & 1374 \\
\hline 0.0977 & 0.7310 & 826 & 1077 & 0.2507 & 0.3096 & 702 & 1347 \\
\hline 0.1098 & 0.6977 & 871 & 1153 & 0.2711 & 0.2533 & 598 & 1294 \\
\hline 0.1249 & 0.6561 & 905 & 1226 & 0.2968 & 0.1827 & 448 & 1211 \\
\hline 0.1419 & 0.6092 & 923 & 1288 & 0.3231 & 0.1102 & 276 & 1107 \\
\hline 0.1602 & 0.5588 & 926 & 1338 & 0.3461 & 0.0468 & 121 & 1011 \\
\hline 0.1811 & 0.5012 & 906 & 1372 & & & & \\
\hline \multicolumn{8}{|c|}{$x_{1}^{\prime}=0.4619$} \\
\hline 0.0987 & 0.7864 & 644 & 864 & 0.2401 & 0.4802 & 802 & 1338 \\
\hline 0.1091 & 0.7638 & 687 & 931 & 0.2644 & 0.4275 & 762 & 1353 \\
\hline 0.1218 & 0.7363 & 729 & 1001 & 0.2909 & 0.3702 & 703 & 1353 \\
\hline 0.1363 & 0.7049 & 768 & 1072 & 0.3214 & 0.3042 & 612 & 1330 \\
\hline 0.1529 & 0.6690 & 801 & 1142 & 0.3518 & 0.2383 & 497 & 1283 \\
\hline 0.1720 & 0.6276 & 825 & 1209 & 0.3828 & 0.1712 & 361 & 1216 \\
\hline 0.1930 & 0.5821 & 835 & 1266 & 0.4143 & 0.1030 & 216 & 1141 \\
\hline 0.2163 & 0.5317 & 827 & 1310 & 0.4412 & 0.0448 & 87 & 1072 \\
\hline \multicolumn{8}{|c|}{$x_{1}^{\prime}=0.4848$} \\
\hline 0.1103 & 0.7725 & 654 & 892 & 0.2691 & 0.4449 & 757 & 1337 \\
\hline 0.1216 & 0.7492 & 691 & 953 & 0.3085 & 0.3637 & 665 & 1330 \\
\hline 0.1342 & 0.7232 & 742 & 1031 & 0.3509 & 0.2762 & 536 & 1292 \\
\hline 0.1538 & 0.6827 & 784 & 1116 & 0.3939 & 0.1875 & 377 & 1226 \\
\hline 0.1766 & 0.6357 & 809 & 1190 & 0.4331 & 0.1067 & 213 & 1146 \\
\hline 0.2012 & 0.5850 & 823 & 1257 & 0.4617 & 0.0477 & 89 & 1084 \\
\hline 0.2328 & 0.5198 & 809 & 1311 & & & & \\
\hline \multicolumn{8}{|c|}{$x_{1}^{\prime}=0.6623$} \\
\hline 0.1668 & 0.7482 & 553 & 809 & 0.3523 & 0.4680 & 671 & 1211 \\
\hline 0.1844 & 0.7216 & 594 & 877 & 0.4046 & 0.3891 & 621 & 1241 \\
\hline 0.2077 & 0.6864 & 633 & 951 & 0.4580 & 0.3084 & 538 & 1240 \\
\hline 0.2362 & 0.6434 & 663 & 1025 & 0.5182 & 0.2175 & 419 & 1214 \\
\hline 0.2689 & 0.5940 & 681 & 1093 & 0.5693 & 0.1404 & 297 & 1170 \\
\hline 0.3063 & 0.5375 & 688 & 1158 & 0.6206 & 0.0629 & 163 & 1115 \\
\hline \multicolumn{8}{|c|}{$x_{1}^{\prime}=0.7786$} \\
\hline 0.2334 & 0.7002 & 465 & 718 & 0.4889 & 0.3721 & 444 & 973 \\
\hline 0.2615 & 0.6641 & 492 & 775 & 0.5529 & 0.2898 & 374 & 972 \\
\hline 0.2953 & 0.6207 & 511 & 831 & 0.6205 & 0.2030 & 277 & 948 \\
\hline 0.3339 & 0.5711 & 520 & 881 & 0.6870 & 0.1176 & 162 & 905 \\
\hline 0.3808 & 0.5109 & 514 & 926 & 0.7469 & 0.0407 & 57 & 865 \\
\hline 0.4322 & 0.4449 & 489 & 957 & & & & \\
\hline
\end{tabular}

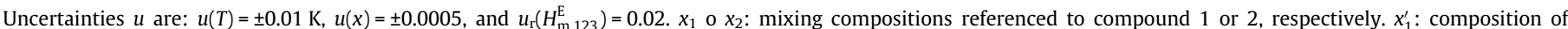

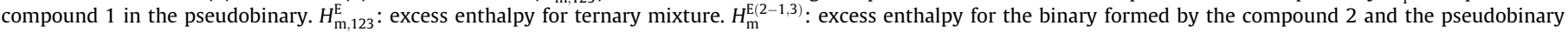
(methyl pentanoate $(1)+$ methanol (3)).

endothermic, with $H_{\mathrm{m}}^{\mathrm{E}}>0$, but quantitatively different because of the type of interactions taking place. In addition to the results for the binaries (methyl-ester + methanol), those obtained for (este$\mathrm{r}+$ ester) binaries are also of interest, see figure $1(\mathrm{~b})$, with a maximum close to $400 \mathrm{~J} \cdot \mathrm{mol}^{-1}$ in the case of (methyl pentanoate $(1)+$ methyl methanoate (2)). In figure $1(\mathrm{c})$, the equimolar $H_{\mathrm{m}}^{\mathrm{E}}$ of these systems are compared with others previously published and those obtained additionally to explain the behavior of the mixtures, although not formed part of this work. It can be observed that the increase in ester chain, $R_{1} C O O-R_{2}$, both the acid part $R_{1}$ or the alkanolic $R_{2}$, weaken the (dipole + dipole) interactions, with a resulting drop in the $H_{\mathrm{m}}^{\mathrm{E}}$ values. This decrease also occurs with systems of (esters + alkanols), as shown in figure 1(b). The $H_{\mathrm{m}}^{\mathrm{E}}$ data for the binary (methyl methanoate (2) + methanol (3)) differ from those presented by other authors [21] by around $150 \mathrm{~J} \cdot \mathrm{mol}^{-1}$; the numerical values in that cited study are similar to those given for the binary (methyl pentanoate (1) + methanol (2)). The data were correlated with equation (1) using the parameter $k_{\mathrm{h}}^{\mathrm{j}-\mathrm{i}}$ established by equation (4), with a good quality of fit.

Because of possible relevance of these binaries in some of the processes indicated in the introduction, the $H_{\mathrm{m}}^{\mathrm{E}}$ were estimated by the UNIFAC method [22]. As can be observed in figure 1(b), the estimation of that property for (ester + ester) system is contrary to real values, with the distribution adopting a sigmoidal 

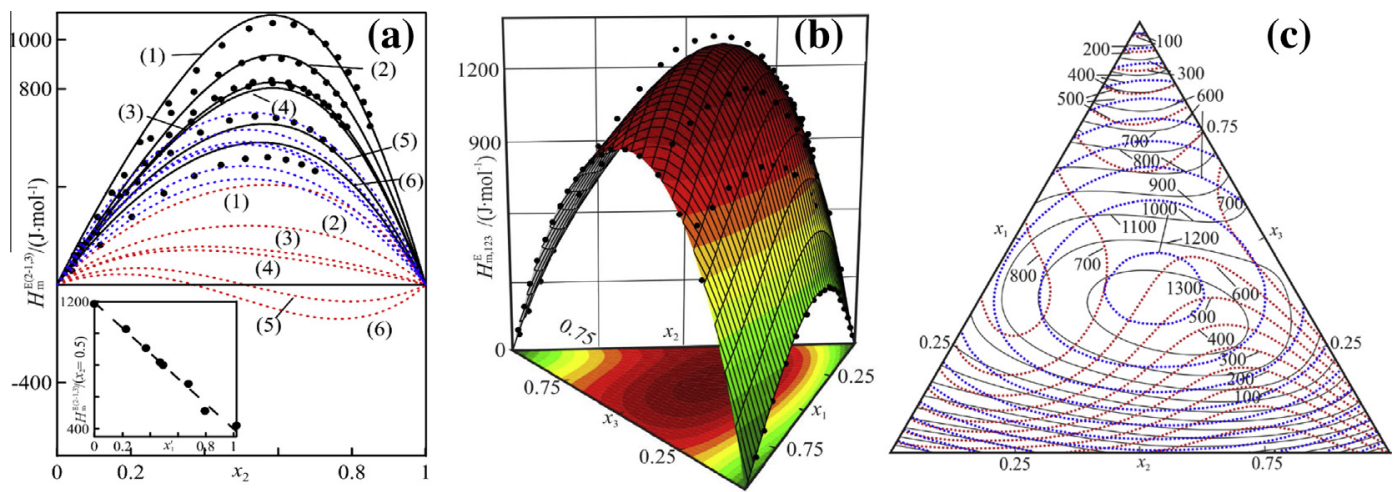

FIGURE 3. Plot of excess enthalpies for ternary solutions formed by: methyl pentanoate (MP), methyl methanoate (MM), methanol (MOH). (a) Plot of $H_{\mathrm{m}}^{\mathrm{E}(2-1,3)}$ obtained by addition of MM (2) on the binary MP + MOH (1,3) whose compositions are: (1) $x_{1}^{\prime}=0.223$, (2) $x_{1}^{\prime}=0.363$, (3) $x_{1}^{\prime}=0.462$, (4) $x_{1}^{\prime}=0.485$, (5) $x_{1}^{\prime}=0.6623$, (6) $x_{1}^{\prime}=0.7786$. Inset represents the regular variation of equimolar $\left(\mathrm{at} x_{2}=0.5\right) H_{\mathrm{m}}^{\mathrm{E}(2-1,3)}$ values as function of $x_{1}^{\prime}$. (b) 3D-Plot for the surface $H_{\mathrm{m} .123}^{\mathrm{E}}=H_{\mathrm{m} .123}^{\mathrm{E}}\left(x_{1}, x_{2}, x_{3}\right)$ obtained by equation $(8)$ and the corresponding experimental values $H_{\mathrm{m} 123}^{\mathrm{E}}$ obtained for the ternary at $T=298.15 \mathrm{~K}$. (c) Isolines corresponding to the horizontal projections of the surface of $H_{\mathrm{m}, 123}^{\mathrm{E}}=H_{\mathrm{m}, 123}^{\mathrm{E}}\left(x_{1}, x_{2}, x_{3}\right)$ represented in (b) for constant values of $H_{\mathrm{m}, 123}^{\mathrm{E}}$ which are indicated by the labels in $\mathrm{J} \cdot \mathrm{mol}^{-1}$. $(\bullet . \cdots \cdots)$ Excess enthalpies by UNIFAC [22], $(\ldots \ldots)$ excess enthalpies by UNIFAC [recalculated].

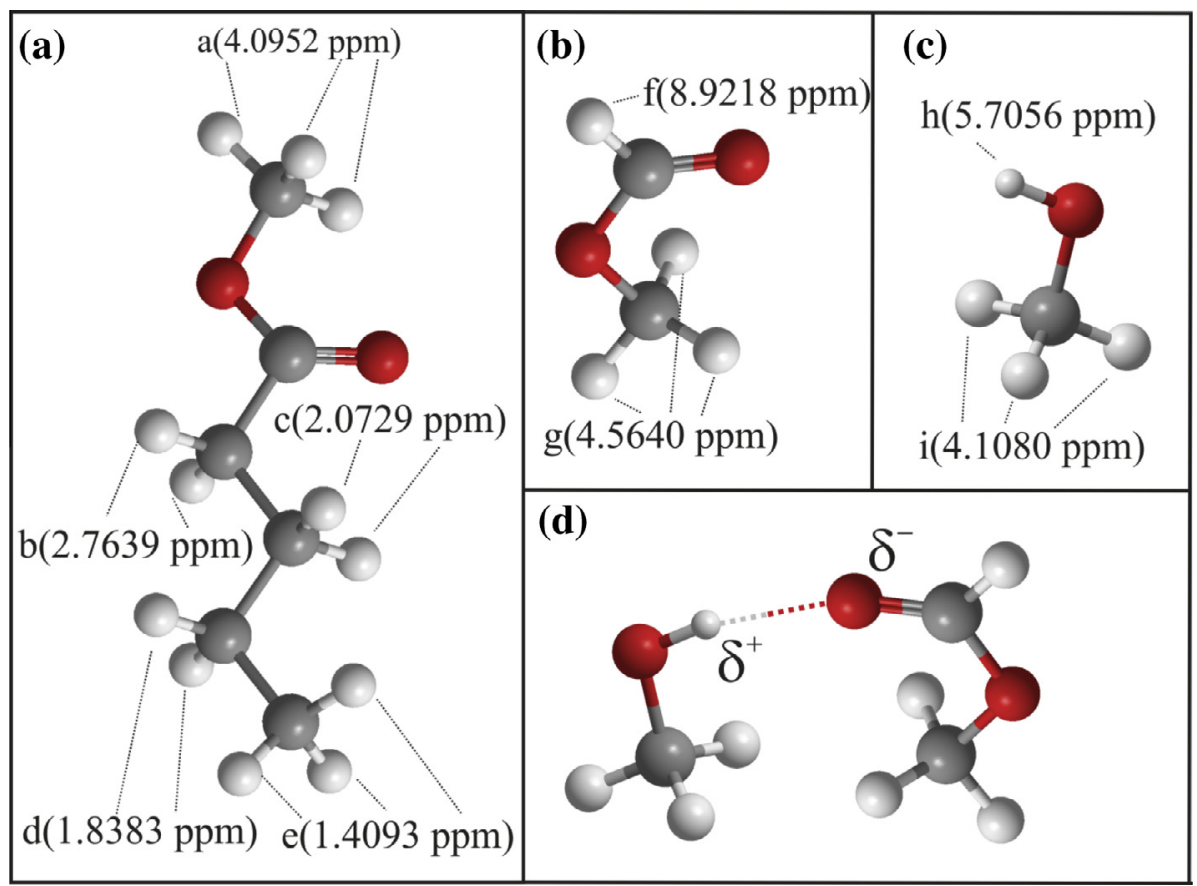

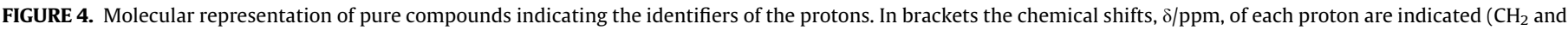

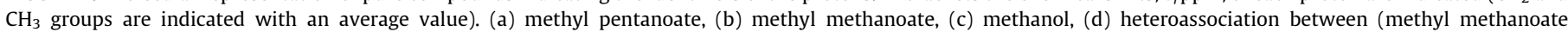
$(2)+$ methanol (3)).

form. The theoretical representation of the $H_{\mathrm{m}}^{\mathrm{E}}$ for the (methyl ester + methanol) is not acceptable either, giving values 30\% lower than experimental values, as the model does not take into account the acid chain length of the methyl alkanoate. The results suggest that the group contribution model must consider the specific interaction, since in some cases is quantitatively significant.

Table 8 shows the experimental data for the ternary $\left(x_{1}, x_{2}, H_{\mathrm{m}, 123}^{\mathrm{E}}\right)$ measured at $T=298.15 \mathrm{~K}$, also showing the specific net energetic effect $H_{\mathrm{m}}^{\mathrm{E}(2-1,3)}$ resulting from adding methyl methanoate (2) to the pseudocompound, which is a synthetic solution of (methyl pentanoate (1) + methanol (3)); from which, six different solutions were prepared $x_{1}^{\prime}$. Figure $3(a)$ shows a graphical representation of that effect, for which $H_{\mathrm{m}}^{\mathrm{E}(2-1,3)}>0$, in all cases. The inset figure shows that the variation in these enthalpic effects (at $x_{2}=0.5$ ) with the composition of the pseudocompound $x_{1}^{\prime}$ is quasilinear, with a negative slope, opposed to the volumes, see figure 2(a). Finally, the global numerical values of the ternary $H_{\mathrm{m}, 123}^{\mathrm{E}}$, are calculated by

$H_{m, 123}^{\mathrm{E}}=H_{\mathrm{m}}^{\mathrm{E}(2-1,3)}+\left(x_{1}+x_{3}\right) H_{\mathrm{m}, x_{1}=x_{1}^{\prime}}^{\mathrm{E}(1,3)}$,

where $H_{\mathrm{m}, x_{1}=x_{1}^{\prime}}^{\mathrm{E}(1,3)}$ is the mixing enthalpy of the binary (methyl pentanoate (1) + methanol (3)) at each composition $x_{1}^{\prime}$ obtained by interpolation of the correlation function calculated previously 

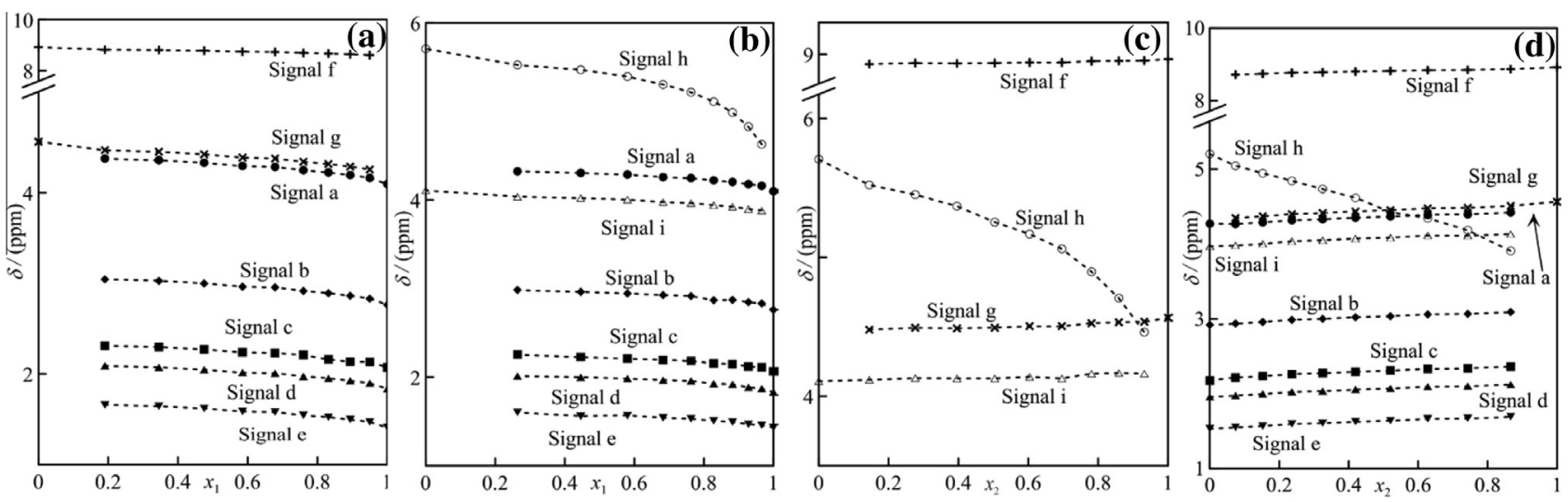

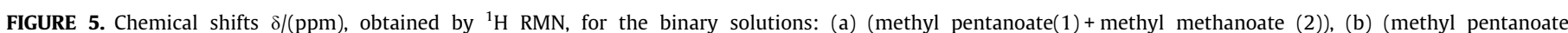

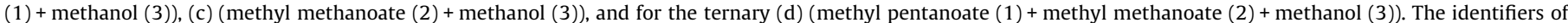

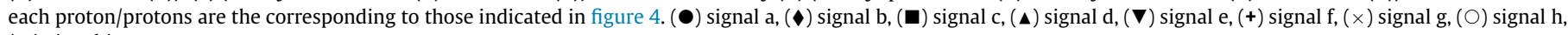
$(\triangle)$ signal i.

for the binary 1-3 (equation (1)). Data for the ternary, shown in table 8 , are positive and are correlated with equation (8), using for the binary contributions (corresponding to the first summand $H_{\mathrm{m}, 2,5}^{\mathrm{E}\left(i_{1}-i_{2}-i_{3} \cdots-i_{n-1}\right)}$ of equation (8)), the equation (1) and the coefficients exposed in table 5 . The $C_{\mathrm{i}}$ coefficients of the ternary are determined as described previously, see table 7. Although the quality of fit is considered to be acceptable, some differences are observed in figure 3(a) with experimental values. Figure 3(b) shows the surface $H_{\mathrm{m} .123}^{\mathrm{E}}=H_{\mathrm{m} .123}^{\mathrm{E}}\left(x_{1}, x_{2}, x_{3}\right)$ represented by function (8) obtained in the fit, with an absolute maximum in the interior $\left(x_{1}=0.204\right.$, $\left.x_{2}=0.438\right)$, reflected by the presence of closed isoenthalpics that appear in the triangular diagram of figure $3(\mathrm{c})$.

The UNIFAC group contribution model transfers the errors made in the binary estimation, already discussed, resulting in inadequate predictions, as shown by the isolines (in red) of the triangular representation.

\section{4. ${ }^{1} \mathrm{H}$ NMR spectral analysis}

A ${ }^{1} \mathrm{H}$ NMR spectral study was carried out and the chemical shifts $\delta$ of protons were observed, for the different compounds studied. The values of these are recorded on the corresponding structures of figure 4(a) to (c), which also shows the characteristic identifier for each signal. Similarly, the corresponding study was also conducted for the binary and ternary mixtures, at known compostions, and the results are shown in figure 5(a) to (d). Diamagnetic or paramagnetic shifts $\Delta \delta$ versus composition for the binary of the two methyl alkanoates (figure 5(a)) are weak, associated with a slight change in polarity of the medium. The two solutions of (methyl ester + methanol), figure 5(b) and (c), show, respectively, small diamagnetic and paramagnetic shifts as the composition of the ester increases, justified by the increase in polarity mentioned, and the anisotropies of the -COO- groups. In the same figures it can be observed that the hydroxylic proton of methanol presents significantly pronounced diamagnetic shifts $(\Delta \delta)$ with the alkanoate composition (signal h), related to an effect of hydrogen bond heteroassociation $\mathrm{OH} \ldots \mathrm{OOC}$, see figure 4(d). This binding is weak compared to the autoassociation of the alkanol molecules, shifting toward greater intensities of magnetic field (reduction of $\delta$ ).

The ternaries were measured for a constant ratio (methyl pentanoate + methanol), generating a pseudocompound, as indicated previously in the determination of properties, to which known quantities of methyl methanoate were added later. The results of the chemical shifts are shown in figure 5(d) relative to the composition $x_{2}$, of the methyl methanoate. As expected, the signal of all the protons is transferred (note the slight increase in paramagnetic shifts) as the methanoate composition increases. The exception to this is seen by the signal corresponding to the proton of $-\mathrm{OH}$ of alkanol that does so diamagnetically (signal h), partially attributable to the anisotropy of the carbonyl group (see figure $5(\mathrm{~d})$ ). The chemical shift in the ternary can be observed to be quantitatively inferior to that of both binaries (figure 5(b) and (c)), reflecting a weaker heteroassociation effect compared to the binaries.

\section{Conclusions}

The properties of $H_{\mathrm{m}}^{\mathrm{E}}$ and $V_{\mathrm{m}}^{\mathrm{E}}$ have been determined experimentally for the ternary comprised of two methyl alkanoates (methanoate and pentanoate) and methanol, and for the corresponding binaries. The data obtained have given rise to the following discussions and conclusions, depending on the nature of the compounds in the solutions.

\section{1. $($ Ester + Ester $)$}

The mixing process of methyl pentanoate with methyl methanoate produces $H_{\mathrm{m}}^{\mathrm{E}}>0$ and $V_{\mathrm{m}}^{\mathrm{E}}>0$, mainly resulting from the (dipole + dipole) interactions and the rupture of the hydrogen bonds of the methyl methanoate (autoassociation). Figure 1(c) collects some equimolar $H_{\mathrm{m}}^{\mathrm{E}}$ values using other binaries (ethyl alkanoates) different to those from this work. All this will be the subject of future research. Using the UNIFAC method $\mathrm{HCOO} /$ COOC interactions were calculated (distinguishing between the ethanoate and non-ethanoate groups) substantially modifying the representation of the model, see figure 1 (b) for the (methyl pentanoate (1) + methyl methanoate (2)) mixture. Obviously, the values found affected positively in the estimation of the energetic interaction of the ternary, as shown in figure 3(c). In summary, the group contribution method should be adequately modified to evaluate the different interactions when compounds of the same chemical nature give place to specific interaction. Spectral data obtained with ${ }^{1} \mathrm{H}$ NMR are coherent with these deductions since, as the amount of pentanoate is reduced, the paramagnetic shifts of the signal are partly due to the decreased polarity of the solution. The weaker interactions, together with the impediment due to the size of the acid chain of the methyl pentanoate, cause empty 
spaces to appear between the molecules in the solution, giving rise to volumetric expansions in these mixtures.

\section{2. $($ Ester + Alkanol $)$}

In the binaries of (methyl methanoate or methyl pentanoate + methanol), the volumetric effects of contraction are noteworthy, and the energetic effects resulting from the mixing process, which in this case would be the algebraic sum of positive (endo) and negative (exo) energetic interactions, the latter characteristic of an aggregation process or a molecular heteroassociation in the final solution. The spectral study by ${ }^{1} \mathrm{H}$ NMR confirms this grouping by showing the formation of pseudo-hydrogen bonds, which are weaker than those corresponding to the auto-association with alkanol. In figure 5(b), signal $\mathrm{h}$ (corresponding to the hydroxylic proton) presents a reduction in the chemical shift in the mixture of (methyl pentanoate (1) + methanol (3)), while in figure $5(\mathrm{c})$, the slope $\left(d \delta / d x_{1}\right)$, corresponding to (methyl methanoate (2) + methanol (3)) is greater than in the previous case, as to be expected. The UNIFAC model does not take into account the specific interactions of these mixtures.

\section{3. $($ Ester + Ester + Alkanol $)$}

In the ternary solution it is necessary to compute the interactions belonging to the pure components, and also those of the binaries. Moreover, the coexistence of molecules from three different species produces a synergy, with differences in the real thermodynamic quantities in the order of those to be expected by summing the effects of the binaries. Figures S1a and S1b (supplementary material) represent, respectively, the values of $\Delta V_{\mathrm{m}, 123}^{\mathrm{E}}$ and $\Delta H_{\mathrm{m}, 123}^{\mathrm{E}}$, which, mathematically, correspond to the last summand of equation (8). These quantities constitute the individual contribution in each of the specified quantities $\left(V_{\mathrm{m}, 123}^{\mathrm{E}}\right.$ and $\left.H_{\mathrm{m}, 123}^{\mathrm{E}}\right)$ due to the simultaneous presence of three components. Hence, the contribution of $\Delta V_{\mathrm{m}, 123}^{\mathrm{E}}$ to the global volumetric effect is small and, generally, positive and decreases with increasing composition of methyl pentanoate, to reach even negative values (see figure S1a). However, the specific contribution of $\Delta H_{\mathrm{m}, 123}^{\mathrm{E}}$ to the overall energetic calculation is more significant (see figure S1b) and, in most cases, corresponds to $11 \%$ of the total amount. This is reflected in an internal maximum in the function $H_{\mathrm{m}, 123}^{\mathrm{E}}=H_{\mathrm{m}, 123}^{\mathrm{E}}$ $\left(x_{1}, x_{2}, x_{3}\right)$, see figure $3(\mathrm{c})$.

\section{Acknowledgments}

This research was supported by a grant from Spanish Government, MINECO, (project CTQ2012-37114).

\section{Appendix A. Supplementary data}

Supplementary data associated with this article can be found, in the online version, at http://dx.doi.org/10.1016/j.jct.2015.02.019.

\section{References}

[1] J. Ortega, J.D. García, Can. J. Chem. 66 (1988) 1520-1524.

[2] J. Ortega, J.L. Legido, J. Fernández, M. López, L. Pias, M.I. Paz, Fluid Phase Equilib. 56 (1990) 219-234.

[3] M. Chaar, J. Ortega, J. Placido, E. González, ELDATA: Int. Electron. J. Phys. Chem. Data 1 (1995) 191-208

[4] E. González, J. Ortega, J. Chem. Eng. Jpn. 28 (1995) 765-771.

[5] E. González, J. Ortega, J. Chem. Eng. Data 41 (1996) 53-58.

[6] A.M. Blanco, J. Ortega, J. Chem. Eng. Data 43 (1998) 638-645.

[7] F. Espiau, J. Ortega, E. Penco, J. Wisniak, Ind. Eng. Chem. Res. 49 (2010) 95489558.

[8] N. Pérez, L. Fernández, J. Ortega, F. Toledo, J. Wisniak, J. Chem. Thermodyn. 54 (2012) 41-48.

[9] G. Giardino, R.M. Jimeson, M.C. Radosevich, R.R. Stevens, Mixed alcohol fuels for internal combustion engines, furnaces, boilers, kilns and gasifiers and slurry transportation, US Patent 20130019519 A1, 2013.

[10] Y. Deng, Fuel additives effectively improving fuel economy, US Patent 20120192484 A1, 2013.

[11] Y. Chen, Fuel additive, US Patent 20110107657 A1, 2011.

[12] C. Beatrice, G. Di Blasio, M. Lazzaro, C. Cannilla, G. Bonura, F. Frusteri, F. Asdrubali, G. Baldinelli, A. Presciutti, F. Fantozzi, Appl. Energy 102 (2013) 6371.

[13] D. Bradin, G.L. Grune, M. Trivette, Alternative fuel and fuel additive compositions, US patent 20090013591 A1, 2009.

[14] P. Klezl, Fuel for internal combustion engines and use of methyl formats as fuel additive, EU Patent EP 501097 A1, 1992.

[15] M.J. Stickney, E.M. Jones, M.S. Chandrasekharalah, S. Kumar, Fuel blend for an internal combustion engine, US Patent 6923839 B2, 2005.

[16] J. Hill, E. Nelson, D. Tilman, S. Polasky, D. Tiffany, Proc. Natl. Acad. Sci. USA 103 (2006) 11206-11210.

[17] M. Lapuerta, O. Armas, J. Rodríguez-Fernández, Prog. Energy Combust. 34 (2008) 198-223.

[18] C.J. Hayes, D.R. Burgess, Proc. Combust. Inst. 32 (2009) 263-270.

[19] H.V. Kehiaian, R. Bravo, M. Pintos, M.I. Paz, R. Guieu, J.-P.E. Grolier, Fluid Phase Equilib. 17 (1984) 187-216.

[20] J. Polak, B.C.-Y. Lu, J. Chem. Thermodyn. 4 (1972) 469-476.

[21] M. Lopez, J. Fernandez, F. Sarmiento, J.L. Legido, L. Romani, E. Jimenez, M.I. Paz, J. Chem. Thermodyn. 24 (1992) 809-814.

[22] U. Weidlich, J. Gmehling, Ind. Eng. Chem. Res. 26 (1987) 1372-1381.

[23] J. Ortega, S. Matos, M.I. Paz, E. Jimenez, J. Chem. Thermodyn. 17 (1985) $1127-$ 1132.

[24] J.A. Riddick, W.B. Bunger, T. Sakano, Organic Solvents: Physical Properties and Methods of Purification, fourth ed., Techniques of Chemistry, WileyInterscience, New York, 1986.

[25] TRC Thermodynamic, Tables Non-Hydrocarbons \& Hydrocarbons. Thermodynamic Research Center, Texas A\&M University System, CollegeStation, Texas, 1965.

[26] J. Ortega, F. Espiau, J. Tojo, J. Canosa, A. Rodríguez, J. Chem. Eng. Data 48 (2003) $1183-1190$.

[27] K.N. Marsh, R.H. Stokes, J. Chem. Thermodyn. 1 (1969) 223-225.

[28] A. Bondi, Physical Properties of Molecular Liquids, Crystal and Glasses, Wiley, New York, 1968.

[29] M.L. Connolly, J. Appl. Cryst. 16 (1983) 548-558.

[30] M.L. Connolly, J. Mol. Graphics 11 (1993) 139-141.

JCT $14-453$ 